\title{
Use of RAPD-PCR for breed/genotype identification in Zimbabwean cattle
}

\author{
Christine Mhuka ${ }^{\mathrm{a}}$, Fungayi P. Chatiza ${ }^{\mathrm{a}, *}$, Farisai Chidzwondo $^{\mathrm{b}}$, Idah Sithole-Niang ${ }^{\mathrm{b}}$, \\ Stanley Makuza a and Sibonani S. Mlambo ${ }^{\mathrm{c}}$ \\ a Department of Animal Production and Technology, School of Agricultural Sciences and Technology, \\ Chinhoyi, Zimbabwe \\ ${ }^{\mathrm{b}}$ Department of Biochemistry, University of Zimbabwe, Harare, Zimbabwe \\ ${ }^{\mathrm{c}}$ Department of Biotechnology, School of Agricultural Sciences and Technology, Chinhoyi, Zimbabwe
}

\begin{abstract}
Lack of resources for characterization and the indiscriminate crossbreeding of cattle in Africa have led to the loss of some breeds. This study was aimed at screening for polymorphic primers for cattle breed identification in Zimbabwe. The Nguni and other local breeds have suffered genetic losses due to indiscriminate crossbreeding. Genetic characterization and semen cryopreservation are important in conservation and breeding programs. Genomic DNA was extracted from whole blood using a DNA extraction kit and was amplified using RAPD-PCR. A total of 8 primers was screened and five (OPX-15, OPB-04, OPG-07, OPG-12 and OPD-02) were polymorphic and three (OPD-01, OPB-05 and OPB-09) were monomorphic, as revealed by agarose gel electrophoresis. RAPD-PCR was found to be effective in detecting the polymorphisms within the bovine species. The polymorphic primers can be used to determine genotype variations in crossbred animals to determine genotype variations in different breeds.
\end{abstract}

Keywords: Bovine, polymorphic, characterization, RAPD-PCR

\section{Introduction}

Various types of indigenous cattle are found in Zimbabwe. The Tuli and Mashona are the main indigenous breeds and some of the exotic breeds include: the Brahman, Hereford and Sussex [1]. There has been indiscriminate cattle breeding in Zimbabwe since 2000 due to random movements of cattle from different farms. Indiscriminate breeding can affect reproductive performances in bulls by causing semen quality variations. Therefore, it is important to screen Randomly Amplified Polymorphic Deoxyribonucleic acid (RAPD) primers so as to identify polymorphic ones that can be used ascertain the genotypes in the cattle. Indiscriminate crossbreeding has led to the extinction [2], of for instance, the Nguni cattle breed [1] and the emergence of non-descript breeds.

Molecular markers are unaffected by selection forces and are therefore suitable for characterizing closely related genotypes [3]. Screening of molecular markers gives a reliable basis for predicting similarities or differences [4] in cattle. For effective breeding programmes and conservation to be carried out, it is very crucial to screen RAPD primers so as to ascertain the genotypes in the cattle. Closely related genotypes can effectively be distinguished using molecular markers based upon deoxyribonucleic acid (DNA) sequence variations. The polymerase chain reaction (PCR) technique has introduced the use of amplified DNA sequences as molecular markers, by using very little template DNA [5, 6].

\footnotetext{
*Corresponding author: Fungayi P. Chatiza, Department of Animal Production and Technology, School of Agricultural Sciences and Technology, Private Bag 7724, Chinhoyi, Zimbabwe. Tel.: +263 067 22203/Ext. 268 or +263 772739202; E-mail: Fungayi.chatiza@gmail.com.
} 
Morphological and phenotypic traits, for example, the chest-humped and long-horn cattle have been used in traditional diversity assessment. Phenotypic descriptors poorly characterize closely related genotypes and are also affected by environmental factors [3]. Therefore, screening of RAPD markers is crucial for testing genotype identity.

Classification by use of molecular markers reliably gives unbiased estimates of the overall similarities and/or differences between breeds [4]. PCR, which was developed by Kary Mullis in the 1980s, is a three step process involving denaturation, annealing and extension [7]. During Random Amplified Polymorphic Deoxyribonucleic acid-Polymerase Chain Reaction (RAPD-PCR) annealing, a random primer of arbitrary sequence will bind on particular complementary priming sites of the template genomic DNA, thereby producing amplicons if the priming sites are in an amplifiable distance with each other [2, 8]. The RAPD analysis method was developed by Williams et al. [9] and, in the process, short oligonucleotide primers will amplify a range of fragments from a template DNA in PCR reactions that have a lowered annealing temperature [10]. The RAPD PCR is a method of identifying polymorphisms for genetic mapping and strain identification. It is a preferred method because it is (a) less expensive than other previous methods such as protein markers that have been used to determine genetic variations, (b) faster and (c) it does not require prior sequence information. The ability of RAPDs to survey multiple loci has been used to analyse genetic distance as well as phylogeny reconstruction. RAPDs are a strong tool in the DNA fingerprint analysis of different animal species, population analyses, gene mapping and identification of breeds $[7,11,12]$.

The knowledge of genetic variation is required for characterization of breeds so that effective breeding programs within and between populations can be done [13]. The RAPD technique has been successfully used in characterizing bovine populations $[2,14,15]$. Other studies which have used RAPD markers include: those carried out for the Japanese black cattle (Wagyu), Zebu cattle, German native cattle as well as for the Korean native cattle [16]. According to [17], RAPD markers have also been an important tool in linkage analysis of poultry. In this study, RAPD primers have been screened so as to identify polymorphic primers for Zimbabwean cattle breeds. This information is relevant for the development of conservation and breeding program for Zimbabwe. Therefore, it is of utmost importance to identify RAPD primers that can be used to ascertain the genotypes in the cattle.

\section{Materials and methods}

\subsection{Blood collection}

Blood was collected from 11 cows using a syringe and $18 \mathrm{G}$ needle after sterilizing the area with $70 \%$ ethanol. The blood was quickly transferred into ethylenediaminetetraacetic acid (EDTA) blood tubes and inverted 5 times, gently to avoid clotting. The blood tubes were then kept in a cooler box on ice and transported to the laboratory within 30 minutes, where blood was stored in a freezer at $-20^{\circ} \mathrm{C}$.

\subsection{DNA extraction}

Blood was thawed at room temperature and DNA was extracted from the blood using the ZR Genomic DNA ${ }^{\mathrm{TM}}$-Tissue MiniPrep (D3050 and D3051) kit. Blood samples (100 $\mu$ l) were pipetted into a microcentrifuge tube before adding $2 \mathrm{X}$ Digestion buffer $(95 \mu \mathrm{l})$ and Proteinase $\mathrm{K}(5 \mu \mathrm{l})$. The solution was mixed and the tubes incubated in a water bath (Sigma Techware) at $55^{\circ} \mathrm{C}$ for 20 minutes. Genomic Lysis Buffer $(700 \mu \mathrm{l})$ was added to the tube and mixed thoroughly by vortexing. The mixture was transferred to a Zymo-Spin ${ }^{\mathrm{TM}}$ IIC Column in a collection tube and centrifuged at $10000 \mathrm{~g}$ for one minute using an eppendorf 5415D centrifuge. In a new collection tube, DNA Pre-Wash Buffer 
(200 $\mu \mathrm{l})$ was added to the spin column and centrifuged for a minute, after which g-DNA Wash Buffer $(400 \mu \mathrm{l})$ was added and centrifuged for one minute at $10000 \mathrm{~g}$. The spin column was transferred to a clean microcentrifuge tube. DNA Elution Buffer $(\geq 50 \mu \mathrm{l})$ was added to the spin column and incubated for 2-5 minutes at room temperature, then centrifuged at $12000 \times \mathrm{g}$ for 30 seconds to elute the DNA. The eluted DNA was then amplified using a thermocycler (2720 Applied Biosystems).

\subsection{RAPD-PCR reaction}

RAPD-PCR was performed in a 2720 Applied Biosystems thermocycler. Each reaction was in a final volume of $25 \mu \mathrm{l}$, containing 1X PCR buffer $(2.5 \mu \mathrm{l}), 25 \mathrm{mM} \mathrm{MgCl}_{2}(1.5 \mu \mathrm{l}), 2.5 \mathrm{mMdNTP}$ mix $(2.0 \mu \mathrm{l}), 10 \mu \mathrm{M}$ primer $(1 \mu \mathrm{l})$, template DNA $(1 \mu \mathrm{l})$ and 5 units of Taq DNA Polymerase $(0.5 \mu \mathrm{l})$.

Amplification of DNA proceeded with initial denaturation at $91^{\circ} \mathrm{C}$ for 4 minutes, 38 cycles of denaturation at $91^{\circ} \mathrm{C}$ for 1 minute, annealing at $42^{\circ} \mathrm{C}$ for 15 seconds, and extension at $72^{\circ} \mathrm{C}$ for 70 seconds followed by an additional extension at $72^{\circ} \mathrm{C}$ for 5 minutes. The amplification products were separated by electrophoresis on $1.5 \%$ agarose gels in $1 \mathrm{X}$ Tris base, acetic acid and EDTA (TAE) buffer in the presence of ethidium bromide for 45 minutes at $150 \mathrm{~V}$.

\subsection{Gel electrophoresis}

Agarose gel (1.5\%) was made by dissolving (3.0 g of agarose powder dissolved in $200 \mathrm{ml}$ TAE buffer $(1 \mathrm{X})$ ). A heated magnetic stirrer was used to stir the gel in a conical flask covered with aluminium foil until it had completely dissolved. When the gel was still hot, $6 \mu$ l of ethidium bromide $(10 \mathrm{mg} / \mathrm{ml})$ was added and mixed with the agarose solution to give a homogeneous solution. The solution was left to cool until the conical flask could be held in the hands then poured into the gel box (Galileo Biosystems). After the gel had solidified, it was suspended in 1X TAE buffer. The RAPD-PCR product (25 $\mu \mathrm{l}$ ) was mixed with $5 \mu \mathrm{l}$ loading dye (6X Orange DNA loading Dye) to make $30 \mu \mathrm{l}$, then $15 \mu \mathrm{l}$ was loaded into the wells. A volume of $10 \mu \mathrm{l}$ Hind III marker was loaded into the first well. Distilled water $(12 \mu \mathrm{l})$ was loaded into the last well as a control. Gel electrophoresis was carried out for approximately 45 minutes at $150 \mathrm{~V}$ until the dyes had trisected the gel. Visualization of the bands was carried out using a UV transilluminator and the results were photographed using a Kodak Edas 290 digital camera.

\section{Results}

RAPD-PCR was carried out with 8 primers, OPD-01, OPD-02, OPB-04, OPB-05, 0PG-07, OPB09, OPG-12 and OPX-15. Of the 8 primers, five primers (OPX-15, OPB-04, OPG-07, OPG-12 and OPD-02) were polymorphic and three (OPD-01, OPB-05 and OPB-09) were monomorphic. Table 1 below shows the average number and size of bands obtained from the different random primers.

Primers 0PG-07 and OPX-15 showed higher degree of polymorphism than primers OPB-04, OPG12 and OPD-02. A distinct band of about $2322 \mathrm{bp}$ was amplified with the primer OPB-04. Apart from the distinct band, OPB-04 also showed another band size, which was present in lanes 2, 6 and 8. Of the 5 different banding patterns, lanes 1,9 and 11 showed similar bands, lanes 3 and 7 also had similar bands, as did lanes 2 and 4. Lanes 5 and 6 showed banding patterns that were unique to all others. The 125 bp band sizes were common to the different breeds present, showing that some of the animals were crossbreeds and that they were related. Figure $1 \mathrm{a}$ and $1 \mathrm{~b}$ below show the gel pictures of the polymorphic and the monomorphic primers respectively. 
Table 1

Average number and size of bands obtained from different random primers

\begin{tabular}{lcccc}
\hline Primer & $\begin{array}{c}\text { Sequence } \\
\left(5 '-\ldots-\ldots-\ldots 3^{\prime}\right)\end{array}$ & GC\% & $\begin{array}{c}\text { Average number } \\
\text { of bands }\end{array}$ & $\begin{array}{c}\text { Size } \\
\text { range (bp) }\end{array}$ \\
\hline OPD-01 & 5'-CTGGGGCTGA-3' & 70 & 32 & $564-24000$ \\
OPD-02 & 5'-GGACCCAACC-3' & 70 & 16 & $125-2027$ \\
OPB-04 & 5'-GGACTGGAGT-3' & 60 & 19 & $125-564$ \\
OPB-05 & 5'-CTGGGCACGA-3' & 70 & 40 & $125-2027$ \\
OPG-07 & 5'-GAACCTGCGG-3' & 70 & 43 & $125-2500$ \\
OPB-09 & 5'-AATGCCGCAG-3' & 60 & 33 & $125-1500$ \\
OPG-12 & 5'-CAGGCACTGA-3' & 60 & 11 & $2500-9416$ \\
OPX-15 & 5'-CAGACAGCC-3' & 60 & 8 & $700-1700$ \\
\hline
\end{tabular}

\section{Discussion}

Conventional methods, such as protein markers, of genotypic characterization of cattle have proven to be complex, time consuming and difficult to interpret their results, as compared to molecular genomic analysis such as RAPD-PCR [18]. Molecular DNA polymorphisms are preferred for the assessment of genetic diversity among livestock breeds [19]. The results show polymorphic primers (Fig. 1a) OPX-15, OPB-04, 0PG-07, OPG-12 and OPD-02 as the suitable primers to differentiate between cattle breeds or confirm the genotypes in crossbred animals. RAPD-PCR has several advantages which make it the molecular technique of choice in African countries.

The process is cost effective, reliable and efficient. It does not require prior knowledge of the DNA under analysis and it only uses small amounts of genomic DNA. When selecting the most suitable primers for use in RAPD analysis it is best to select primers with ten nucleotides and a G-C content of at least $50 \%$ because primers having a high A-T content may cause melting of the DNA-primer complex during polymerization at $72^{\circ} \mathrm{C}[16]$.

While screening the 8 primers, primers OPX-15, OPB-04, OPG-07, OPG-12 and OPD-02 showed polymorphisms, indicating possible differences between the different cattle breeds or specificity for certain genotypes. This means that when these primers are run against control samples, genotypic differences become apparent in cross bred animals. The monomorphic primers, OPD-01, OPB-09 and OPB-05 did not show any polymorphisms, thus cannot be used to characterize genotypic differences between breeds used in this study.

Primer OPD-01 has been shown to produce polymorphic bands by [20] in their study on Yunnan cattle breeds. Interestingly, the primer produced monomorphic bands in this study. This may have been due to the genotypic differences in the breeds present in this study. The phenotypic characteristics of the breeds used in the study indicate that the animals may be crossbreeds of Tuli and Brahman, Tuli and Mashona or Brahman and Mashona. The polymorphisms shown with the primer OPB-04 reveal that 3 types of the available breeds were differentiated. Another band size, of $125 \mathrm{bp}$ was common to all the breeds. This shows that the breeds are related or that this band size is specific for these cattle.

The polymorphisms of OPD-02 show the presence of 2 different breeds. Primer OPG-07 showed 5 different banding patterns. This reveals the presence of 5 different breeds or genotypes. Primer 0PG-07 produced a total number of 8 polymorphic bands with a size range of $400-1475 \mathrm{bp}$ in a study done on Rathi and Thaparkar Indigenous Cattle (Bos Indicus) cattle breeds by Sharma et al. [21]. Likewise, primer OPG-07 can effectively be used to characterize different cattle breeds based on genotypic differences present as shown in this study. 
OPG-07

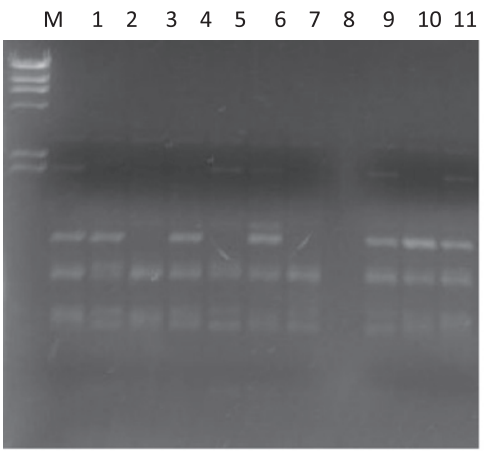

OPX-15

$109877 \quad 6 \quad 5 \quad 4 \quad 32 \quad 1 M$

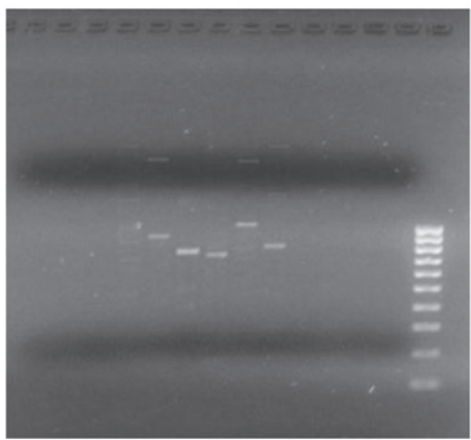

OPB-04

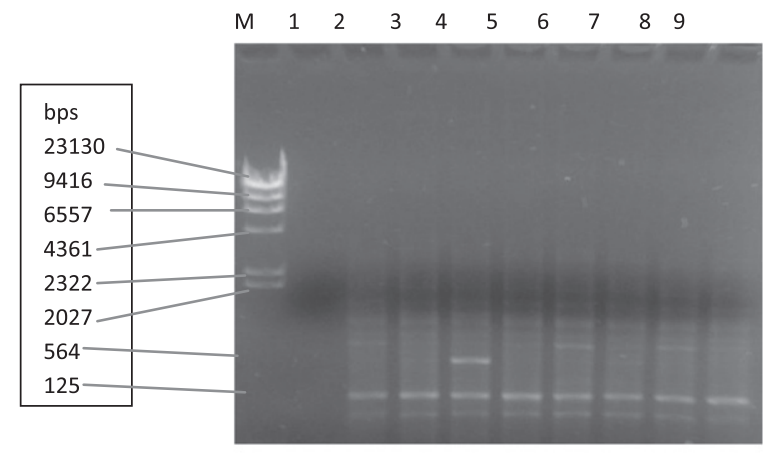

OPD-02

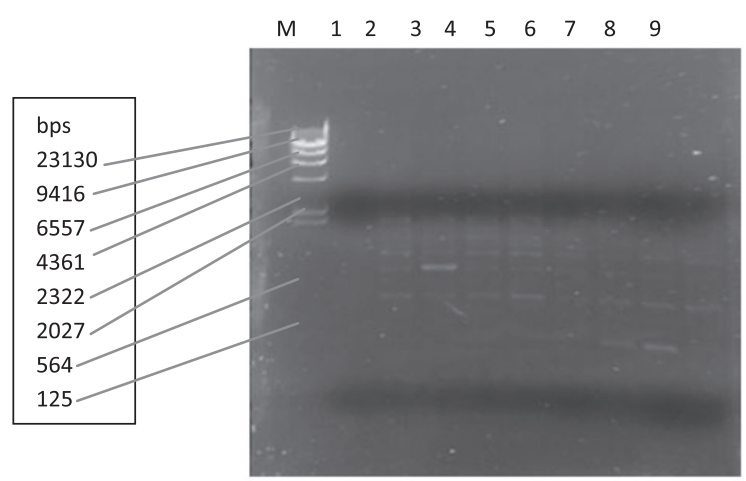

OPG-12

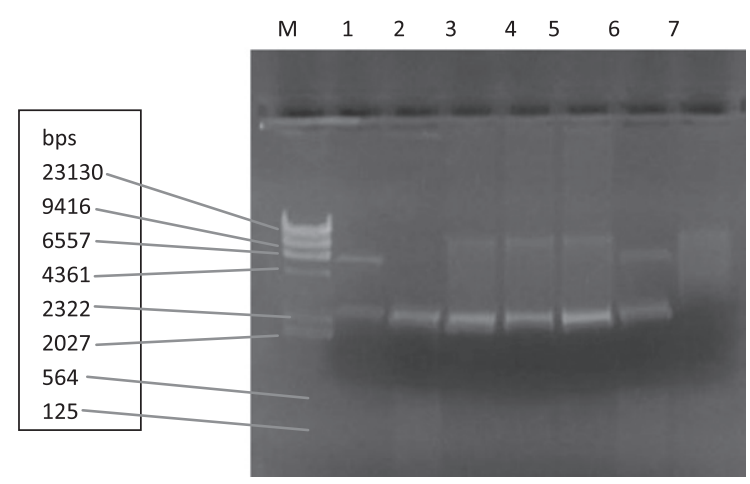

Fig. 1a. Agarose gels showing polymorphic primers (OPX-15, OPB-04, 0PG-07, OPG-12 and OPD-02).

The polymorphic pattern shown by OPG-12 showed the presence of 3 different breeds as shown by the 3 different banding patterns. Lanes 1 and 6 had similar band sizes, lanes 3, 4 and 5 are also similar but lane 2 only had one $2500 \mathrm{bp}$ band, which was common to all the breeds present, thus showing relatedness or species specificity. OPX-15 produced a remarkable polymorphic pattern. A polymorphic pattern was obtained from 5 lanes of the gel, thus showing the presence of 5 different breed types.

OPX-15 produced a common band size of about $130 \mathrm{bp}$ in two of the breeds, showing that they were related. The common band size showed that although the two animals were crosses of two different 


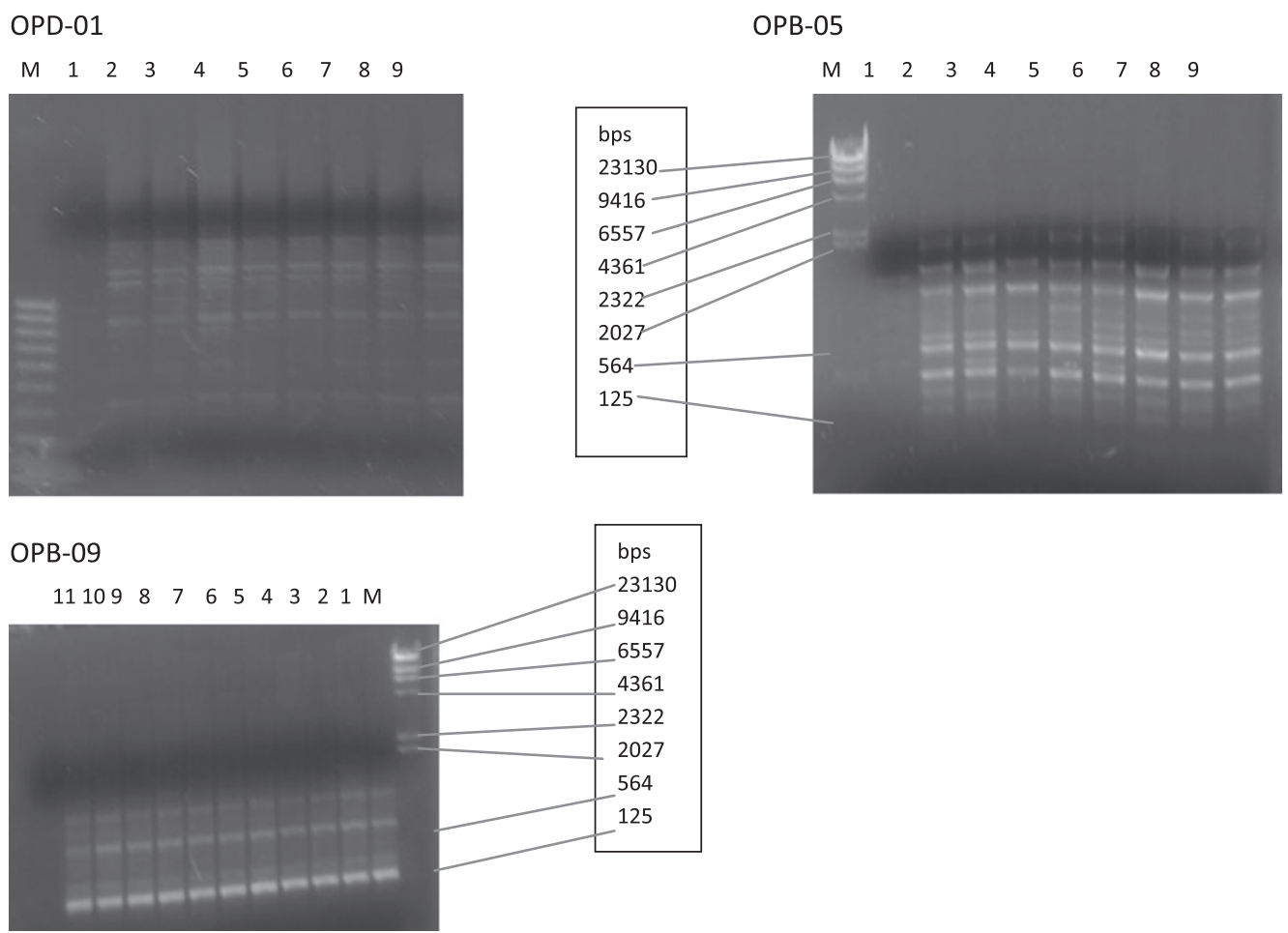

Fig. 1b. Agarose gel pictures showing monomorphic primers (OPD-01, OPB-09 and OPB-05).

breeds, they had genetic material from a common ancestor. Despite the remarkable polymorphisms obtained with OPX-15, some lanes could not show even a single band. This may have been due to non-specific binding during RAPD-PCR, or maybe the template DNA of the breeds present did not have the priming sites for OPX-15. This study gives baseline information on the type of primers that can be used for genetic variability analysis of Tuli, Mashona, Brahman and possibly Nguni cattle breeds in Zimbabwe.

\section{Conclusions}

RAPD-PCR proved to be effective in detecting the polymorphisms within the bovine species. Primers (OPD-02, OPB-04, OPG-07, OPX-15, and OPG-12) showed polymorphisms and can therefore determine genotype variations in crossbred animals whereas primers (OPD-01, OPB-05 and OPB-09) were monomorphic and cannot determine genotype variations. Primer OPD-01 shown to be polymorphic for Yunnan breeds was monomorphic in this study. Polymorphic primers revealed relatedness of some of the available breeds. Primers OPG-07 and OPX-15 showed higher degree of polymorphism than primers OPB-04, OPG-12 and OPD-02 therefore primers OPG-07 and OPX-15 can effectively characterize different cattle breeds.

\section{Acknowledgments}

The authors would like to thank the Chinhoyi University of Technology for providing the research grant for the project as well as the Biotechnology and the Animal Production and Technology 
Departments' laboratory staff members. We would also like to acknowledge the University of Zimbabwe's Biochemistry Department for providing the equipment as well as personnel to assist with the protocols, special mention goes to Ian R Munhenzva. The authors would also like to acknowledge the Grasslands Research Station for providing us with the cattle blood samples.

\section{References}

[1] Tawonezvi P, Makuza S, Moyo S, Nengomasha E. Zimbabwe Country Report on the state of the World's Animal Genetic Resources, 2004.

[2] Gwakisa PS, Kemp SJ, Teale AJ. Characterization of zebu cattle breeds in tanzania using random amplified polymorphic markers. Anim Gene 1994;25:89-94.

[3] Matthew S. Molecular Profiling of Bauhinia Accessions using RAPD Markers. International Journal of Pharma and Biosciences 2010;1(4):B-199-B207.

[4] Hassen F, Bekele E, Ayalew W, Dessie T. Genetic variability of five indigenous Ethiopian cattle breeds using RAPD markers. African Journal of Biotechnology 2007;6(19):2274-9, Addis Ababa, Ethiopia.

[5] Munthali M, Ford-Loyd BV, Newbury J. The Random Amplification of Polymorphic DNA for fingerprinting plants. School of Biological Sciences, University of Birmingham. Cold Spring Harbour Laboratory Press. Birmingham. UK, 1992.

[6] Weber JL, May PE. Abundant class of human DNA polymorphisms which can be typed using the polymerase chain reaction. Am J Hum Genet 1989;44:388-96.

[7] Karp G. Cell and Molecular Biology Concepts and Experiments: Structure and function of plasma membrane. Sixth Edition. John Wiley and Sons. New York, 2009.

[8] Hardys H, Balick M, Schierwater B. Applications of random amplified polymorphic DNA (RAPD) in molecular ecology. New York Botanical Garden, Bronx, USA, 1992.

[9] Williams JGK, Kubelik AR, Livak KJ, Rafiski JA, Tingey SV. DNA Polymorphisms amplified by arbitrary primers are useful as genetic markers. Nucleic Acids Res 1990;18:6531-5.

[10] Ramesha KP, Saravanan T, Rao MK, Appannavar MM, Obi Reddy A. Genetic Distance among South Indian Breeds of Zebu Cattle Using Random Amplified DNA Markers. SRS of NDRI, Adugodi, Bangalore. India, 2001.

[11] Barwar A, Sangwan ML, Kumar S, Ahlawat S. Genetic diversity between Murrah and Bhadawari breeds of Indian Buffalo using RAPD-PCR. College of veterinary sciences CCS Haryana University of Agricultural University, Hisar India. Banking. New York: Academic Press, 2008, pp. 1-25.

[12] Govarthanan M, Guruchandar A, Arunapriya S, Selvankumar T, Selvam K. Genetic variability among Coleus sp. studied by RAPD banding pattern analysis. Int J Biotechnol Mol Biol Res 2011;2:202-8.

[13] Hetzel DJS, Drinkwater RD. The use of DNA techniques for the conservation and improvement of animal genetic resources. FAO Expert Consultation on the management of global Animal Genetic Resources. Rome, Italy, 1992.

[14] Kemp SJ, Teale AJ. Random Amplification DNA Polymorphisms and pooled DNA in bovine genetic Studies. Anim Gene 1992;23(suppl 1):62.

[15] Kemp SJ, Teale AJ. Randomly primed PCR amplification of pooled DNA reveals polymorphism in a ruminant repetitive DNA sequence which differentiates Bos indicus and B. taurus. Animal Genetics 1994;25:83-88.

[16] Yeo JS, Lee JS, Lee CH, Jung YJ, Nam DH. Identification of genetic markers for Korean Native Cattle (Hanwoo) by RAPD Analysis. Eunpyung-ku, Seoul, Korea, 2000.

[17] Hwang KC, Song KD, Kim TH, Jeong DK, Sohn SH, Lilleo HS, Han JY. Genetic linkage mapping of RAPD markers segregating in Korean ogol chicken- white leghorn backcross population. Asian - Aust J Anim Sci 2001;14 (3):302-6.

[18] Sarkar A, Saha M, Patra A, Roy P. Characterization of Aeromonas hydrophila through RAPD-PCR and SDS-PAGE Analysis. Open Journal of Medical Microbiology 2012;2(2), Article ID: 19633, 4 pages DOI:10.4236/ojmm.2012.22005

[19] Zulu D. Genetic Characterization of Zambian Native Cattle Breeds. Virginia Polytechnic Institute and state University, 2008.

[20] Yu Y, Lian L-S, Wen J-K, Shi X-W, Zhu F-X, Nie L, Zhang Y-P. Genetic diversity and relationship of yunnan native cattle breeds and introduced beef cattle breeds. Plenum Publishing Corporation. China, 2004.

[21] Sharma AK, Bhushan B, Kumar S, Kumar P, Sharma A, Kumar S. Molecular Characterization of Rathi and Thaparkar Indigenous Cattle (BosIndicus) Breeds by RAPD-PCR. Animal Genetics Division, Indian Veterinary Research Institute, Izatnagar, Bareilly - 243 122, Uttar Pradesh, India, 2004. 